\title{
Entre idealismo moral e realismo político: Beauvoir em busca de uma síntese (im)possível?
}

\author{
Between Moral Idealism and Political Realism: \\ Beauvoir in search of an (im)possible synthesis?
}

\author{
Thana Mara de Souza \\ Docente do Departamento e Programa de \\ Pós-Graduação em Filosofia da UFES
}

Resumo: O artigo pretende expor e discutir, a partir dos textos dos anos 1940 e centrado principalmente em Idealismo Moral e Realismo Político, o modo como Beauvoir traz as noções de idealismo e realismo, moral e política, apontando para uma concilianção tensa entre eles, sempre a ser construída e nunca alcançável. Diante de dois opostos que caem em um mesmo erro (o de considerar apenas o aspecto de uma subjetividade abstrata ou apenas o aspecto de uma objetividade determinista), a filósofa traz o tema da ambiguidade como fundamental para pensar as relações e também separações entre moral e política, admitindo, ao mesmo tempo, uma projeção futura (transcendência) e uma realização presente (imanência).

Palavras-Chave: Beauvoir; Idealismo Moral; Realismo Político.

Abstract: The article intends to show and discuss, from the 1940s texts and focusing mainly on Moral Idealism and Political Realism, how Beauvoir brings the notions of idealism and realism, moral and political, leading for a tense conciliation between them, always to be 
built and never achievable. In the presence of two opposites arguments that commit the same error (one considers only the aspect of an abstract subjectivity and the other, only the aspect of a deterministic objectivity), the philosopher brings the theme of ambiguity as fundamental to think about relations and also separations between morality and politics, conceding, at the same time, a future projection (transcendence) and a present realization (immanence).

Keywords: Beauvoir; Moral Idealism; Political Realism.

\section{Introdução:}

H possível pensarmos em vários modos de abordarmos os asEpectos de uma crítica política feminista. Dentre todos os possíveis, escolhi um que pode parecer, à primeira vista, menos militante ou mais tímido, mas que tem como objetivo discutir filosoficamente um texto de uma filósofa.

Se nas universidades brasileiras de filosofia estamos conseguindo criar um espaço mais consolidado de discussão sobre questão de gênero e sobre a importância de divulgar e pesquisar filósofas, desnaturalizando a ideia de que filosofia é feita apenas por homens; é preciso dar passos variados nesse trabalho, no sentido de mostrar que falar de um pensamento escrito por mulher não significa necessariamente falar da questão de gênero, porque corre-se um risco de criar um nicho, como se o único tema trabalhado por mulheres fosse o fato de sermos mulheres.

Isso é ainda mais aparente quando pensamos em Simone de Beauvoir. Falar em Simone de Beauvoir é quase sinônimo de falar em $O$ segundo sexo, e imediatamente nos vêm à mente a frase "ninguém nasce mulher, torna-se mulher" (Beauvoir, 2016, p. 11). Não podemos negar a importância desse livro para a questão de gênero em meados do século XX e hoje; mas também é necessário compreender que esse livro se insere em uma corrente filosófica específica, e que sua autora traz noções que devem ser compreendidas a partir de onde se coloca, ou seja, a partir da fenomenologia francesa. Com todo o alcance 
político e social que o livro felizmente tem, e que devemos continuar a explorar, não devemos, porém, esquecer que se trata de um ensaio filosófico e que, como tal, insere-se em um lastro teórico que não pode ser ignorado nem menosprezado.

E é esse aspecto que pretendo trabalhar nesse artigo: mostrar como a discussão de Beauvoir sobre a condição das mulheres insere-se em uma discussão moral e política presentes em outros ensaios, e que não deveria ser ignorada. Não compreenderemos de fato o alcance do pensamento beauvoiriano se não trouxermos as noções teóricas que ela trabalha e como ela constrói, em diálogo com a tradição filosófica moderna e contemporânea (principalmente Kant, Hegel, Heidegger, Merleau-Ponty e Sartre) ${ }^{74}$, sua própria filosofia.

O segundo sexo foi publicado em 1949, final de uma década na qual Beauvoir escreveu principalmente textos morais e políticos. Sempre partindo de questões concretas, a filósofa traz temas clássicos da filosofia para modificá-los, para pensá-los ligados ao caráter histórico e contingente da realidade humana. Na contramão de uma filosofia de sobrevoo, sem interesse por metafísicas e ontologias, Beauvoir assume como ponto de partida de seu pensamento aquilo que há de mais concreto: a situação. Por isso, vemos que em seus textos dos anos 40, é recorrente as referências a uma França situada em uma guerra mundial e em um pós-guerra. E isso não é algo que se dê à revelia, mas que é o próprio objetivo de Beauvoir. Como ela mesma afirma no prefácio ao livro $O$ existencialismo e a sabedoria das nações, de 1948: "Toda a conduta viva é uma escolha filosófica, e a ambição de uma filosofia digna desse nome é a de ser um modo de vida que traga consigo a sua justificação" (Beauvoir, 2008, p. 18).

Uma filosofia digna é, pois, aquela que se revela em um modo de vida, tornando impossível dissociar o pensamento teórico de posicionamentos morais e políticos, embora cada um deles tenha sua especificidade. E é o que Beauvoir tenta realizar nos anos 1940: diversos ensaios e artigos em torno de questões morais que terminarão por culminar na questão cen-

$74 \quad$ Filósofos mais comumente citados em seus artigos sobre moral e política e também no ensaio sobre a condição das mulheres. 
tral do feminismo no final da década. Assim, é importante que compreendamos esse caminho teórico e prático para melhor vermos a amplitude da filosófa.

Embora Beauvoir conte com inúmeros e bons comentadores, a maior parte da bibliografia secundária ainda está muito centrada em observações gerais, que abrangem de forma genérica todas suas obras, ou então centrada principalmente em $O$ segundo sexo e na questão da condição das mulheres. Falta, ainda, um debate mais exegético de alguns de seus textos. Assim, na falta de um debate mais aprofundado, na falta de uma análise mais estrutural de seu pensamento filosófico, proponho-me a fazer uma primeira aproximação, seguindo mais de perto o texto da própria Beauvoir e lançando hipóteses de leitura sobre sua filosofia política, de modo a propiciar um começo de debate mais filosófico de seu pensamento moral e político.

Em 1944, no ensaio Pirro e Cinéias, vemos o início da discussão em torno da alteridade e da relação entre presente-futuro, já numa tentativa de anunciar, ao mesmo tempo, a situação e a projeção, a transcendência e a imanência, esse jogo entre liberdade e facticidade: "Decerto que a violência existe. Um homem é ao mesmo tempo liberdade e facticidade; ele é livre, mas não desta liberdade abstrata posta pelos estóicos, ele é livre em situação" (Beauvoir, 2005, p. 182), temas esses que reaparecem com insistência em toda a segunda metade da década de 40. Em 1946, em "Olho por olho", essa dualidade específica (que não pode ser compreendida tal como as dualidades modernas, porque de fato não se pode separar o que é diferente) reaparece nos termos de vingança-justiça. Assistindo ao julgamento de Brasillach, escritor colaboracionista que foi condenado ao fuzilamento após a guerra, Beauvoir explica porque se recusou a assinar uma petição em favor da comutação da pena do acusado. Embora todo o aparato jurídico formal tornasse distante as ações cometidas pelo escritor, embora aquele senhor julgado se distanciasse dele mesmo anteriormente, era preciso garantir que sua pena fosse cumprida. Muito antes de Eichmann em Jerusalém, de Hannah Arendt, vemos Beauvoir colocar-se como aquela que assiste aos depoimentos e julgamentos, e justifica sua decisão, apesar do formalismo do 
direito, de não se juntar a Mauriac e Camus na solicitação de perdão a Brasillach, de defender a justiça no lugar da vingança, apontando, porém, as armadilhas dessa justiça idealista.

Em 1947, vemos essas questões serem formuladas em termos de uma noção que será, a partir de então, fundamental no pensamento de Beauvoir: a ambiguidade. Com a escrita do livro Por uma moral da ambiguidade, a filósofa descreve o quanto a história da filosofia tenta refugiar-se nos opostos, ou em uma subjetividade pura e abstratamente livre, ou em uma objetividade fixa e determinista; recusando a angústia, mas também a riqueza, da ambiguidade. E no mesmo período em que Sartre se debate com a questão da autenticidade ${ }^{75}$, Beauvoir, de modo mais claro e direto, mostra que: "mais do que uma superação hegeliana, trata-se aqui de uma conversão (...) Para atingir sua verdade, o homem não deve tentar dissipar a ambiguidade de seu ser, mas, ao contrário, aceitar realizá-la" (Beauvoir, 2005, p. 18).

Acentuando a "tensão constante" (Beauvoir, 2005, p. 27) de um homem que não cria o mundo, não escolhe sua facticidade (e por isso entendam o lugar, época em que nasce, assim como seu próprio corpo), que, por sua vez, só existe enquanto desvelada pela realidade humana, como vivida; Beauvoir descreve essa liberdade que só pode ser compreendida como movimento de libertação em um mundo dado e diante do olhar dos outros, que nos alienam à nossa revelia. Não por acaso, ao falar do senhor e do escravo hegeliano, a filósofa começa a fazer menção à situação das mulheres, às quais não é dada a possibilidade de exercerem sua liberdade - questão essa que se tornará central em menos de 2 anos depois, momento da publicação de $O$ segundo sexo.

É, pois, nesse contexto teórico e social que o ensaio sobre a condição feminina é escrito. E é também em meio a esses questionamentos e diálogos que em 1945 Beauvoir escreve o artigo "Idealismo moral e realismo político", o qual passaremos a analisar a partir de agora.

$75 \quad$ Sartre aponta em $O$ ser e o nada a necessidade de pensar a autenticidade, mas só chegará a elaborar um esboço do que ela seria em Cadernos para uma moral, livro inacabado e publicado postumamente. 


\section{Os dualismos aparentemente opostos:}

Beauvoir começa seu artigo, publicado na Revista Tempos Modernos, colocando em cena Antígona contra Creonte, no clássico dilema entre o direito divino e o direito da pólis. Partindo do que os próprios personagens dizem (e não inicialmente do que sua filosofia tem a dizer sobre eles), a filósofa mostra Antígona como protótipo da moralista instransigente, que pretende conservar a pureza da sua consciência - em confronto com Creonte, o protótipo, por sua vez, dos políticos cínicos, apenas preocupado "com os interesses da cidade e decidido a defendê-los não importa por que meios" (Beauvoir, 2008, p. 41). E, sem desenvolver essas imagens (e poderíamos dizer que, a partir da fenomenologia beauvoiriana, ambos na verdade erram e que, quer queiram ou não, ambos estão inseridos na concretude, que não elimina a liberdade), Beauvoir nos traz ao século $\mathrm{XX}$, dizendo que, se não temos mais tanto o dilema entre o divino e a cidade, temos, no entanto, outros dilemas, e o posicionamento diante deles permanece, na maior parte das vezes, idêntico ao de Creonte e Antígona.

Diante das dualidades contemporâneas de subjetividade/coletividade; classe/nação, futuro/presente,

muitos deles procuram refúgio numa destas duas atitudes opostas, mas igualmente incapazes de os libertar de si mesmos: um moralismo intransigente, ou um realismo cínico; no primeiro caso, escolhem obedecer a uma necessidade interior, encerram-se na mais pura subjetividade; no segundo caso, decidem submeter-se à necessidade das coisas; perdem-se na objetividade (Beauvoir, 2008, p. 43).

Se o moralista idealista proclama sua subjetividade pura e se recusa a agir nas condições que se apresentam, porque não são as condições ideias (como se isso fosse possível); o político realista proclama a objetividade determinista e se recusa a valorar os meios para se atingir o fim, já ditado pelas circunstâncias, de modo que se trata apenas de obedecer ao que a situação exige (como se no próprio fato estivesse o sentido do fato). E ambos estariam, na visão de Beauvoir, errados. De certo modo, optando por escolhas opostas, ambos acabam por cair no mesmo erro: no de escolher apenas um dos lados da 
equação, de colocar um termo como dado, determinado, sem relação com o outro.

Assim, a moral clássica, outro modo de Beauvoir de descrever essa escolha por uma subjetividade pura (a atitude de Antígona), herança mais ou menos adulterada da moral kantiana, se mostraria indiferente, preocupada em manter-se pura, e portanto, estéril, por optar por não se posicionar, por ver vantagens em se abster de questões concretas, dado que elas não se adequam às exigências abstratas. Em outras palavras, é como se, não aceitando os meios para chegar aos fins projetados, porque não ideais, desistíssemos do próprio fim. Ao não aceitar nenhum meio que não seja o meio ideal, abstrato, absoluto, o moralista instransigente abdica do próprio fim que busca - salvando, assim, sua pura subjetividade, mas com o preço de nada modificar.

No entanto, segundo Beauvoir, nem mesmo aqueles que defendem essa moral intransigente acreditariam nela, de modo que não seria difícil se opor a ela. Assim, fica-se estabelecido, a partir da fenomenologia à la francesa (que interpreta o ir às coisas mesmas não no sentido estrito husserliano, de pensar apenas no modo de doação, mas na realidade de fato do objeto visado), que o realismo ganha do idealismo. O que não significa optar pelo realismo, mas que, de partida, é a concretude que tem maior peso.

É por isso que, depois de fazer uma breve apresentação desse moralismo intransigente e puro, que se recusa a sujar as mãos em nome de sua subjetividade pura, Antígona, Beauvoir se concentra na descrição e crítica ao realismo político, porque, embora o ponto de partida seja a realidade, o modo como ambos - filósofa e político cínico - entendem essa realidade é muito distinto.

Podemos dizer que, tanto para Beauvoir quanto para o realismo político, é preciso lidar com questão singular e concreta, de forma que essa moral idealista se apresenta como estéril e obstáculo; e que ambos acentuam o caráter histórico e contingente das coisas humanas: 
Empenhado no presente, ocupado a construir o futuro, o político sente o caráter histórico e contingente das coisas humanas e nega à moral qualquer caráter absoluto e intemporal; esta esforça-se por se retirar para fora do tempo, mas, ao fazê-lo, relega-se simplesmente para o passado, apresenta-se como uma inútil herança dos tempos idos; querendo-se absoluta, corta as suas raízes terrenas, e o homem de ação, enraizado na terra, já não descobre nela qualquer fundamento (Beauvoir, 2008, p. 45).

No entanto, se o ponto de partida é comum - a concretude e singularidade das situações - não podemos simplesmente alocar Beauvoir como uma realista. E isso porque, para ela, o realismo erra ao optar pelo outro extremo: no de transformar o fim em um fim absoluto dado e determinado, de modo que, ao inverso mas mesmo movimento do idealista, qualquer meio valeria para o fim absoluto a ser atingido. Esses realistas políticos, ou políticos cínicos, assumem que os fins são impostos de fora, e que a própria realidade dita as regras do que deve ser feito, de modo que qualquer ato é possível e viável para se alcançar esse fim.

O político realista se coloca como um técnico, apenas pensa nas estratégias - todas elas possíveis - para alcançar o fim que já está definitivamente estabelecido pela própria circunstância. O fim a ser atingido, que a própria situação define, determina as ações a serem realizadas. É exatamente o que os colaboracionistas franceses fizeram: declarando que a derrota da Alemanha era impossível (o fim determinado pela própria circunstância), optaram pelo meio possível: colaborar. Se não há outra possibilidade final que não a vitória da Alemanha, então o melhor meio possível é aliar-se a ela o mais cedo possível.

Assim é que o realista político age. Nesse sentido, nada mais longe do pensamento de Beauvoir:

Claro que a ocupação da França pela Alemanha era uma realidade, mas era real também que os franceses continuavam a ser livres de dar a esse acontecimento o sentido que escolhessem, se todos tivessem colaborado, a Alemanha ter-se-ia tornado uma aliada; se resistissem, continuariam a ser adversária (Beauvoir, 2008, p. 49).

Se não se pode negar que havia uma facticidade não escolhida - a ocupação da França pela Alemanha; também não se 
deveria negar, segundo Beauvoir, que o sentido dessa ocupação não era determinado pela própria ocupação. Colaborar não era aceitar o que era inevitável pela circunstância, mas era dotar de um sentido o fato atual, projetando sua continuação.

Mas não nos enganemos. Não apenas os conservadores são alinhados a essa política cínica. Para Beauvoir, há ao menos duas espécies desse realismo político, que coloca o que é objetivo como aquilo que define toda ação: o realismo conservador, da burguesia; e o realismo revolucionário, que instaura a noção de revolução desagregada dos movimentos que a engendram, como se não importassem os meios para se chegar a ela. Ambos pensam que o caçador se interessa mais pela lebre do que pela caça, enquanto, para Beauvoir (2008, p. 53), "na verdade, o caçador interessa-se pela lebre que ele caça; há aí uma totalidade indissolúvel". Desse modo, se os realistas de esquerda acertam ao denunciar os idealistas e realistas de direitas, eles também erram ao colocar o fim como aquilo que justifica qualquer ato para a ele se chegar.

Ao fazer uma interpretação naturalista de uma atitude política, os realistas cínicos caem em contradição: "mais uma vez [falando do realista revolucionário], encontramos no realismo essa contradição flagrante: por respeito à realidade, nega essa realidade na qual todos os outros encontram o seu valor e o seu sentido: a realidade humana" (Beauvoir, 2008, p. 54).

Se os idealistas morais são relativamente fáceis de serem criticados porque nem eles mesmos acreditam no grau de pureza e abstração que reclamam, os realistas políticos, ao proclamarem o ponto de partida contrário - a realidade -, também caem no erro de tentar reduzir uma relação a apenas um dos termos. Em outras palavras, esses políticos cínicos tentam fazer, da política, uma atitude natural, suprimindo a doação de sentido que as subjetividades dão ao fato.

Na relação entre meios e fins, é como se os idealistas recusassem a alcançar o fim porque nenhum meio é ideal o suficiente para suas almas puras; e como se os realistas recusassem a valorar o meio porque o fim é ditado objetivamente e deve 
ser, então, obedecido a qualquer custo. Ao contrário de ambos, Beauvoir coloca que

é impossível dissociar o fim do meio. O meio só se compreende à luz do fim pretendido, mas, inversamente, o fim é solidário do meio pelo qual se actualiza, e é falso que se possa chegar a um fim através de não importa que meio. O realista retrata mal a relação do meio com o fim: pensa o fim como uma coisa fixa, fechada em si mesma, separada do meio, que é definido, também ele como uma coisa, um simples instrumento (Beauvoir, 2008, pp. 54, 55).

Para Beauvoir, é preciso sair desses dualismos e optar pela ambiguidade. Se, por um lado, nem todo fim justifica os meios; por outro, não se deve utilizar um meio que destrói o próprio fim a ser alcançado. Quando um partido de esquerda, por exemplo, busca o poder para implementar seus programas, deve-se admitir quais meios para se chegar a esse fim? Valeria entrar totalmente no jogo de tal modo que o próprio programa a ser implementado é destruído no jogo de favores no Congresso? Para Beauvoir, não. Mas também valeria uma recusa da tentativa de alcançar o fim projetado porque todos os meios implicam em sujar as mãos? Para Beauvoir, também não. Fins e meios são uma totalidade indissolúvel, são uma teia ligando o presente ao futuro.

Para expressar essa ligação, Beauvoir lança mão de uma noção que reaparece em seus textos e ganhará, em $O$ segundo sexo, uma importância muito grande: o corpo. ${ }^{76}$ Do mesmo modo que o corpo é, ao mesmo tempo, uma força mecânica e a expressão de nossa existência, nossos atos se inserem ao mesmo tempo como fenômenos materiais e como realidade sig-

\footnotetext{
76 A noção de corpo entrelaçado entre liberdade e facticidade, como expressão e mecânica, é fundamental a ser trabalhada no pensamento de Beauvoir, para pensarmos qual feminismo seria possível pensar a partir dela. A meu ver, esse feminismo admitiria um peso da facticidade, uma impossibilidade de anular um corpo estruturado na diferença, sem, no entanto, fazer dessa diferença uma determinação. Talvez Beauvoir se afaste de alguns feminismos mais contemporâneos, que trazem uma subjetividade toda poderosa, capaz de anular as facticidades impressas no corpo; e, em seu lugar, propusesse uma ênfase mais na significação desse corpo do que em sua anulação. Para essa hipótese, no entanto, seria necessário fazer uma análise aprofundada do capítulo sobre a biologia, presente em $O$ segundo sexo, o que destoa do objetivo deste artigo.
} 
nificante. E idealismo moral e realismo político erram, ambos, ao apontar, um, apenas para o ato como realidade significante, ignorando que ele se insere em fenômenos materiais; e outro, em apontar, apenas para o ato como fenômeno material, ignorando que ele também é uma realidade insiginificante.

Nosso corpo, que biologicamente nos constitui enquanto natureza e não pode ser eliminado enquanto tal - é por isso que Beauvoir insiste tanto em $O$ segundo sexo, nas particularidades do corpo da fêmea que, com sua estrutura hormonal distinta do corpo do macho, é também e ao mesmo tempo, a expressão de nossa existência, aspecto que também não pode ser eliminado. Mais próxima talvez de Merleau-Ponty do que de Sartre nesse aspecto, o corpo é simbólico em Beauvoir como facticidade e transcendência, como o elemento que reúne a subjetividade e a objetividade, aquilo que não escolhemos e que, junto a ele, nos construímos de modo singular e distinto.

Mas tal como o nosso corpo é uma força mecânica capaz de provocar no mundo material efeitos determinados e ao mesmo tempo, no entanto, a expressão de nossa existência, também os nossos atos se inserem na série de fenômenos materiais, porém sendo também realidades significantes (Beauvoir, 2008, p. 55).

Esse corpo livre e determinado, expressão subjetiva e mecânica objetiva, é, para a filósofa francesa, aquilo que mostra de forma clara essa relação ambígua, esse dilema das nossas ações, que são, ao mesmo tempo, inseridas em um mundo não escolhido, com desenvolvimentos não previstos, mas que, nem por isso, deixam de ser projeções subjetivas que valoram o mundo de uma forma ou outra. Não se trata, aqui, de pensar em uma subjetividade que tudo pode, que é absoluta no sentido abstrato, tal como Antígona, mas também não se trata de, tal como Creonte, colocar-se como um técnico que pretende anular sua subjetividade. Nem subjetividade total, nem objetividade total: a subjetividade existe em um mundo já determinado, com olhares que nos alienam, com um corpo que não escolhemos - e só nesse mundo, nessa facticidade, é que é possível falar em subjetividade. 
Realidade significante e fenômeno material, o ato insere-se nas redes do determinismo e também da liberdade, coloca-se tal como uma teia na qual não distinguimos mais o que é um aspecto ou outro, mas que não existe sem os dois aspectos. É preciso pensar na unidade do projeto, e isso significa que o fim só existe porque projetado subjetivamente, mas que, para realizá-lo, é preciso agir em um mundo, com e contra outros, de forma que nossos próprios atos nos escapam, se objetificam.

O fim visado é sempre uma situação humana, ou seja, um fato significante; os atos que tendem a constitui-lo devem, pois, ao mesmo tempo, criar uma coisa e revesti-la de um sentido; o insucesso é tão total se a coisa não for animada por nenhum sentido, quanto se o sentido não conseguir encarnar-se (Beauvoir, 2008, p. 55).

Uma coisa não animada e um sentido que não se encarna são esses opostos escolhidos pelo realista político e pelo idealista moral que, para fugir do dilema, se refugiam em soluções fáceis. Para Beauvoir, é preciso destacar ao mesmo tempo que a coisa é animada pela subjetividade (contra os realistas políticos) e que o sentido só faz sentido se encarnado em uma coisa (contra os idealistas morais), de forma que, uma política não pode ser cínica, mas deve reconhecer suas ligações com a valoração do humano (portanto, com a moral); e que esta, moral, só faz sentido se inserida em uma situação concreta e específica (portanto, ligada à política).

Mas se é preciso pensar em uma moral realista que se ligue à política, e uma política que reconheça que o sentido do fim projetado vem da realidade humana, isso significa que, para Beauvoir, teríamos que alcançar um plano de uma síntese harmonizadora e feliz?

Nem tanto. Como já citado no texto de 1947, em Por uma moral da ambiguidade, não se trata tanto de pensar em termos de superação hegeliana em uma síntese, mas em termos de conversão. Beauvoir aposta no assumir a ambiguidade, e não em resolvê-la, o que significa, aqui, que nada está decidido de antemão. Dizer que moral e política estão "entrelaçadas" é dizer ao mesmo tempo que "sendo todo o ato a ultrapassagem de uma situação concreta e singular, teremos a cada vez de 
inventar de novo um modo de ação que traga em si a sua justificação" (Beauvoir, 2008, p. 60).

Conciliar política e moral não é alcançar uma ética normativa que nos aliviaria da angústia da decisão. Pelo contrário: "reconciliar moral e poítica é, pois, reconciliar o homem consigo mesmo, é afirmar que a cada instante este pode assumir-se totalmente. Mas isso exige que renuncie à segurança que esperava atingir encerrando-se na pura subjetividade da moral tradicional, ou na objetividade da política realista" (Beauvoir, 2008, p. 61). A conciliação é um exercício de assunção da ambiguidade e da tensão, e não uma superação em uma síntese que eliminaria a tensão.

Nesse sentido, se é possível falar em termos de conciliação, ela não aparece para Beauvoir como uma convivência tranquilizadora, que nos salvaria do incômodo de refletir, decidir e agir. Embora haja uma tentativa de falar em uma moral realista que é política e uma política que não existe sem moral realista, não devemos pensar que esses dois termos (moral e política) sairiam do antagonismo e nos levariam a uma síntese que todo conflito resolveria. Essa síntese, nos moldes hegelianos, seria, para Beauvoir, impossível. Mesmo que possamos projetá-la, ela não é realizável. Em outras palavras, algo se perde, e o que se perde não é recuperável.

Assumir a ambiguidade, a conciliação tensa entre moral e política, é assumir também que não podemos partir de condições ideais, que devemos partir do que não escolhemos; mas que, ao mesmo tempo, o fato não determina o modo como lidaremos com ele. Ou seja: liberdade e facticidade estão imbricadas e exigem sacrifícios.

Descer à terra é aceitar a sujidade, a derrota, o horror, é admitir que é impossível salvar tudo; e que o que se perde está irremediavalmente perdido. Quererá isso dizer que precisamos voltar a justificar, pelos fins, seja que meios forem? Não: o que é preciso compreender é que fins e meios formam uma totalidade indissolúvel; o fim é definido pelos meios que dele recebem o sentido; uma ação é um conjunto significante que se estende através do mundo, através do tempo, e cuja unidade não pode ser quebrada. É essa totalidade singular que se trata de, a cada instante, construir e escolher. Compete-nos a nós escolher se é preciso matar um homem para salvar dez, ou se é me- 
lhor deixar morrer dez, para não trair um; nem no céu, nem na terra uma tal decisão está inscrita. O que quer que eu escolha, serei infiel à minha vontade profunda de respeitar a vida humana; porém, sou obrigado a escolher, e nenhuma realidade exterior a mim mesmo me indicará a minha escolha (Beauvoir, 2008, p. 63).

Sem ajuda das leis divinas e sem ajuda das leis da cidade, o ser humano está condenado a escolher, e, na escolha, a valorar o mundo que não escolhe mas que ajuda a construir. A totalidade indissolúvel entre moral e política não está dada, mas deve ser construida e escolhida como totalidade singular que nunca, de fato, estará totalizada. Assim, se por um lado Beauvoir indica a necessidade de conciliar política e moral, idealismo e realismo, é para caminhar no sentido contrário de uma síntese impossível, indicando que devemos perder a esperança de uma reconciliação definitiva, assim como devemos assumir que é um sonho impossível ter meios que sempre concordam com o fim.

E é nesse caminho de escolhas e perdas, de sacrifícios e traições, que nos construímos e construímos o mundo. Assumir a fratura é nosso fardo e "o preço a pagar pela sua presença no mundo, pela sua transcendência e pela sua liberdade" (Beauvoir, 2008, p. 63).

Não há resposta sobre se matar um homem para salvar dez "vale a pena" ou não. Essa decisão deve ser tomada pelas pessoas diante dessa circunstância; e é a ação delas que descreverá a moral por elas escolhidas. Essa moral não se constroi de forma anterior, abstratamente, para depois ser aplicada às circunstâncias. São as circunstâncias que solicitam de nós, ações, e nossa escolha em agir de um modo ou outro é que tornará essa circunstância com um certo valor moral e político.

Há, pois, imbricamento entre ação, pensada como concreta no mundo; e mundo, pensado como dotado de um sentido humano, mas as teias que ligam um ponto a outro são frágeis e devem ser tecidas, agora, por nossas mãos, na insegurança e indecisão, mas agora. 


\section{Referências:}

BEAUVOIR. O existencialismo e a sabedoria das nações. Lisboa: Caos, 2008.

BEAUVOIR. Por uma moral da ambiguidade, seguido de Pirro e Cineias. Rio de Janeiro: Nova Fronteira, 2005.

BEAUVOIR. O segundo sexo. Rio de Janeiro: Nova Fronteira, 2016 (vol. 2). 